\title{
The resilience among suicide attempt survivor
}

\author{
Fatwa Tentama ${ }^{1}$, Tri Wahyuni Sukesi ${ }^{2}$, Surahma Asti Mulasari ${ }^{3}$, Sulistyawati $^{4}$ \\ ${ }^{1}$ Faculty of Psychology, Universitas Ahmad Dahlan, Indonesia \\ ${ }^{2,3,4}$ Faculty of Public Health, Universitas Ahmad Dahlan, Indonesia
}

\begin{tabular}{l}
\hline \hline Article Info \\
\hline Article history: \\
Received Nov 8, 2019 \\
Revised Jun 11, 2020 \\
Accepted Jul 10, 2020 \\
\hline
\end{tabular}

Keywords:

Empathy

Resilience

Self-efficacy

Suicide

Survivor

\begin{abstract}
Suicide incidents in Gunungkidul, Indonesia have increased from year by year. This phenomenon is of great importance to study to find a proper solution. Based on the data it has been found that people who have committed suicide but have been saved (survived). To date, they have managed to survive and carry out their daily activities well. The majority of suicide attempts are caused by unpleasant experiences in the past. The purpose of this study was to assess the resilience of suicide survivors who can be used to motivate people who intend or who survived suicide to get back up. This research used a qualitative approach with a phenomenological method. The location of this research was in Gunungkidul Regency. The subjects of this study were four people who were obtained by using purposive sampling technique. Several in-depth interviews were carried out to collect the data from the respondent. The results show that the factors supporting the resilience of survivors to suicide were the ability to control emotions and impulses, self-efficacy and optimism, the ability to analyze the causes of problems, empathy, and the ability to achieve what was desired.
\end{abstract}

\section{Corresponding Author:}

Fatwa Tentama,

Faculty of Psychology,

Universitas Ahmad Dahlan,

Yogyakarta, Indonesia.

Email: fatwa.tentama@psy.uad.ac.id

\section{INTRODUCTION}

Suicides and attempted suicides in Gunungkidul district have tended to increase in recent years. Suicide is a thought or action that aims to end a life that was done intentionally, starting from suicidal ideation until finally actually committing suicide. Attempts to commit suicide begin with the idea of suicide, threats of suicide, attempted suicide, and committing suicide. Suicide attempts are defined as all acts of self-injury with the purpose of seeking attention, and the desire to make suicide the cause of death listed on the death certificate on him $[1,2]$.

Depression becomes the most dominant cause of suicide. Most teenagers and children who have suicide ideation experience feelings of depression, negative thoughts and anhedonia, and low self-esteem. In addition, family factors can also contribute to suicide ideation. Individuals with families who apply high control, who have a history of psychopathology and history of suicide, and who experience family dysfunction and disharmony are associated with adolescent suicide ideation. Another factor that also influences suicide ideation in adolescents is bullying. Bullying can be a potential risk factor for depression, suicide ideation, and suicide attempts in adolescents for both victims and perpetrators. Problems at school, such as poor academic performance, lack of attendance and negative attitudes towards schools are also related to suicide ideation. Other factors that influence suicide ideation are physical and sexual abuse, alcohol and perfectionism [3]. 
Suicide is usually committed because of physical suffering, such as thinking about how to pay off debt as well as experiencing various spiritual afflictions such as breakups and unfair treatment. Therefore, individuals think that there is no point in living and the only way to get rid of all the burdens in them is to commit suicide. Based on the description above, the inability to face physical and spiritual suffering experienced by some individuals is the trigger for the emergence of suicidal ideation [4]. The results of the Women's Study Center in 2018 showed that in 2001-2017, there were 492 suicides in Gunungkidul Regency, the data included suicide victims who died and suicide victims who survived or attempted suicide [5]. Based on these data, in 17 years, 28-29 suicides occur. In the first five months of 2017, for example, there were 18 suicides which mean there are 3-4 suicides each month on average. If the suicide case is seen in vulnerable time every month, then there is a trend data that shows that suicide cases have increased in the month leading up to the holiday. Then in the month of the entry of the new school year and the month when there are many celebrations. As in the culture of the people of Gunungkidul, they still often count the "good days" to hold several celebrations.

Subdistricts that have the highest number of suicides are economically advanced districts in the Gunungkidul Regency. Wonosari, Semanu, and Playen district are three sub-districts that are economically more advanced than other sub-districts. This breaks the notion that suicide cases occur because of economic problems. This data, therefore, informs that suicides occur in many developed districts, which become a center of economic growth. The number of older people who commit suicide is $44 \%$ while the remaining $56 \%$ is dominated by those in productive age. It also breaks the notion that suicide cases in Gunungkidul Regency are dominated by elderly people over 60 years.

Based on research data from the 2018 Women's Study Center, suicide can occur to anyone with different backgrounds, both individuals of old or young age, male or female, coming from developed or rural areas. The data also informs the existence of people who have attempted suicide, but were rescued and can normally survive until now. These people were able to get up and survive after a suicide attempt due to various unpleasant experiences in the past. The ability to recover from adversity, even without help from other parties and the power to return to its original state, is called resilience. This is what will be raised in this study, namely the resilience of survivors of suicide. This becomes an alternative solution that can be used to motivate people who intend to commit suicide or who also survived suicide to get up and survive [5].

\section{RESEARCH METHOD}

This study employed a qualitative research method. Data were obtained by conducting preliminary observations, followed by in-depth interviews with four informants who were survivors, informants 'parents or family members, and informants' peers. The location of this research is in Gunungkidul Regency, Indonesia. This research was conducted in March-October 2019. The research subjects were survivors of suicide attempts in Gunungkidul Regency.

Data collection techniques used in this study are in-depth interviews. This study uses an interview guide as a research instrument. This interview guide used is specific to the interviewee. It is possible that this in-depth interview process will be conducted by collecting snowballing information from the existing interview guide. The data analysis technique was conducted using the explanation-building technique of all sources examined and evaluated together so that the findings in the case study were a combination of information from different sources. Data analysis was performed by interview transcript analysis and formulating interview results to obtain the desired information. After obtaining a description of the factors that influence suicide behavior, then from the results of the same interview regrouped to find a description of resilience in victims of suicide survivors.

\section{RESULTS AND DISCUSSION}

Not all suicides lead to death. There are a number of cases of attempted suicide that have failed, and they still survive today. The following are the results of interviews with four informants who described the life process that they lived after experiencing a suicide attempt.

\subsection{Informant $1(J)$}

Informant 1 is a male aged around 27 years, with the initial $\mathrm{J}$ Informant conducted a suicide attempt in 2015. A suicide attempt was carried out because of a love problem. The informant experienced insult from the parents of his lover because of his socioeconomic status. He experienced depression and severe pressure due to experiencing insults and verbal abuse on him and his parents. A Suicide attempt was carried out by trying to hang himself. Attempted suicide can be thwarted, and until now the survivor is in a stable state. Several factors support the situation so that informants can live in stable conditions, namely: 


\subsubsection{Emotional regulation and the ability to control impulses}

Emotion regulation is the ability of survivors to be able to regulate their emotions to stabilize their condition when there are stimuli in the form of problems or anything that can shake their emotions. Survivor $\mathbf{J}$ was asked about his ability to control his emotions, and the following is an excerpt from an interview with $\mathrm{J}$ :

A: ... Now, what would it be like if something happened and what would cause emotions to be so easy (smile)?

$J:$... Well if there is a problem now, I will be more able to control it ... I don't think about it really ... so I just think of something useful and positive like working to earn money (laugh).

A: So you forget the problems by working, but what if for example the problem must be solved immediately.

J: (Laugh) ... Yeah sometimes I get stuck and when I get stuck I tell a friend ... (sigh) ... well at least there is a suggestion from a friend.

Based on the results of the interview survivors are able to control emotions better although he diverts more of his emotions with activities, this is one of the efforts demonstrated by $\mathrm{J}$ in managing his emotions.

\subsubsection{Optimism and self-efficacy}

Optimism and self-efficacy are self-acceptance at the time of adversity. Survivor J currently has a sense of optimism and better self-acceptance. This is indicated by the interview excerpt as follows:

J: Because if I stay still, it will add to my mind and mother's, if they are sick I also have to take care.

A: What makes you optimistic?

J: Because I have to support my grandparent and uncle, so I always think about work, for the affairs of women that happened in the past, I think there are many women out there.

A: From all of that, there have been events like that and have moved on, for J to watch events like that, bro? So, don't you feel sad watching yourself? What are you like? How do you see the past experience?

$B$ : The problem first, is used as an illustration and experience, so that it does not happen again, and does not hate myself, which, yes, is only used as an example.

A: After the incident, you lock yourself at home, and friends came to see you, and you feel okay, what lessons do you learn? How do you make the spirit?

B: What makes the spirit, my friend gave bits of advice which helped me a lot ... I can't be like this forever, I have to be optimistic that everything I have already done can not be repeated, finally, I pushed myself forward.

Survivor $\mathbf{J}$ feels that he has a dependant on his life, namely his grandmother and family, so he makes the family as a trigger to get up, be optimistic, and keep trying to improve himself.

\subsubsection{The ability to analyze the cause of problems}

Survivor $\mathbf{J}$ had a problem which he thought was severe, and there was no way out, so there was a suicide attempt. Right now, his condition is much better, $J$ has been able to cultivate his feelings and thoughts when facing a problem. A trying to find the root of the problem that used to cause a suicide attempt, the experience serves as a valuable lesson in his life today. The following is an excerpt from an interview with survivor $\mathrm{J}$ :

\section{A: What makes you optimistic?}

J: Because I have to support my grandparent and uncle, so my mind is just to work, for the affairs of women that happened in the past, I just have moved on, and I think there are many women out there.

A: That makes it a bad experience, right? Does that matter? Become a burden not to socialize?

$J$ : It is not usual, if I want to get to know a woman again, I will first tell the problem that I have experienced so that it does not happen again...

\subsubsection{The ability to empathize}

The ability to empathize is the ability of a survivor $\mathbf{J}$ to provide empathy and tolerance towards others around him. In the current condition, survivor $\mathrm{J}$ is able to empathize well. This is shown by the high concern for grandmother and family, so that survivor $\mathbf{J}$ feels very responsible for them. The following is an interview excerpt:

A: How were you able to move on and get back to your normal activities?

J: I am still a month in the house, then I thought that if I shut myself up after, all the events could not 
returned, so I ventured out of the house.

A: Who was the first time you hang out with?

J: Mr. Wawan.

A: When you locked yourself for a month at home, did you grandparent say or ask something?

J: It's normal, but I'm sad, my mind still hurts.

A: Are there friends who come when you were home?

J: There is, Agus.

A: What do you do when you first work?

J: Get-together, all right.

A: Why is there a passion for working again?

$J$ : Because if I keep quiet, it will add grandmother and mother thoughts, if they are sick I also have to take care...

\subsubsection{Ability to achieve what is intended}

Sense of optimism and confidence gives energy to survivor $J$ to strive to achieve the dreams of his life at this time. Survivor $\mathbf{J}$ currently has several dreams and aspirations that he really wants to achieve by working hard. The following is an interview excerpt:

A: Now, according to you, how do you make money?

J: Odd jobs every day, anything.

A: Not ashamed?

J: As long as I don't steal why should I be ashamed to do work, I have the principle of "Wong nek arep obah yo iso mamah".

A: Is there a desire to have a family?

J: There is, but I want to save first, independent.

A: What is the target age?

$J:$ No.

A: Is there any girl in your mind?

$J$ : Yes, she lives in the same village.

A: For you, how about your past experience?

$J$ : I made the basis for not repeating it again.

\subsection{Informant 2 (S)}

$\mathrm{S}$ is a woman in her 60 s who carried out a suicide attempt in 2003 by drinking rat poison. His suicide attempt was thwarted by his family by taking him to the hospital. The trigger for the incident was a problem with her husband. S's condition is now better. Her endurance to survive until now is quite high and makes her past a valuable lesson. Some of the factors supporting the condition of survivor $\mathrm{S}$ to date in stable condition are as follows:

\subsubsection{Emotional regulation and the ability to control impulses}

Survivor during the incident can not control emotions. But she eventually can move on to start a new life by forgiving her husband.

"... yeah, it's already dead-end. I can't think anymore. Don't remember anything else"

Survivor only felt the pressure of wanting to commit suicide when the incident (because of the same urge) is at odds with her husband. At that time, the survivors felt there was no way out of the problem that occurred. Talks/discussions have been carried out, but due to repetition of the problem the survivor who reached endpoint tries to commit suicide.

"... because of that association, because of the debate with his father. Selling the wardrobe to Mr. Wahono is just because of disagreement"

\subsubsection{Optimism and self-efficacy}

Survivor currently has good optimism and self-efficacy, although she felt there was no way out to the time of the incident. Then about his current view of life, the survivor has started a normal life again by trying to forgive her husband, who mistreated and disputed at that time. Survivor has the full support of the family. The thing that drives survivors to survive is because of their children and grandchildren (family). 
My sister said this "please stop, if you want to report it like that, you will be all-out (money), what you want to sell. yes the older adult said, accept it. Hopefully, tomorrow, the Almighty will avenge, oh, I don't know, that's hit by thunder hahaha (laugh).

\subsubsection{The ability to analyze the cause of problems}

Survivor can analyze the cause of the problem because of a problem with her husband

"... because of that association, because of the debate with his father. Selling the wardrobe to Mr. Wahono is just because of the discussion"

\subsubsection{Ability to empathize}

Survivor has a pretty good empathy ability. The person closest to the survivor is a family (excluding husband). That closeness arises because of the urge to forgive a husband when a problem occurs.

"I have to accept it anyway, what else can I do?"

\subsubsection{The ability to achieve what is intended}

After the suicide attempt, the survivor chose to continue his life with the key to "forgive" the husband and for the sake of "children and grandchildren".

"... slowly improving and opening hearts because remember you already have grandchildren"

\subsection{Informant $3(M)$}

$M$ is a man aged around 42 years. Survivor $M$ has a bad past and he was not trusted by his parents. $\mathrm{M}$ has a conflict of trust and communication with his family and wife. His wife suspected $\mathrm{M}$ of having an affair supported by some evidence. This causes household conflicts. In 2015, M suffered from a narrowing of the arteries in his legs. This disease made the M's leg unfunctional and must be amputated. This amputation of the foot makes $M$ experience a prolonged depression that causes him to carry out a suicide attempt conducted by drinking rat poison. This suicide attempt was discovered by his father and immediately taken to the hospital until finally, $\mathrm{M}$ can be helped. At the moment the survivor condition is better and more stable, some things that support the current $\mathrm{M}$ condition are:

\subsubsection{Emotional regulation and the ability to control impulses}

Before the suicide attempt, $M$ could not control his emotions. M felt very deep despair due to the amputation of his leg. Survivor felt worthless so that everything that happened to him was considered a bad thing. But, now the condition of survivors is much better. M's emotional regulation is better and if a problem occurs $M$ tends to be relieved and surrender everything to God Almighty. The following is an interview excerpt with $\mathrm{M}$ :

A: How about now, sir, if you face problems?

B: Yeahaaaa ... what do you think about the name of a living person, I have a problem, now I use it Casually ... thought but not really, I surrender to the one who has given me life ... I was given this problem for sure I could just be like that ...

\subsubsection{Optimism and self-efficacy}

Feelings of despair were the root of the problem for $\mathrm{M}$ so he made a suicide attempt. But now $\mathrm{M}$ has been able to take lessons from the events he experienced. $M$ feels that everything that happens to him is something that must be done well. The spirit to rise again from his downturn was marked by an effort to start a new business so that he could make money. Survivor also tried to socialize with his neighbors, relatives and new friends in disability organizations. The following is an interview excerpt:

A: What do you feel now sir about having a new life?

M: My sister is very happy now with my condition, even though I have a leg defect but I still have to try to find a living for my family ... (smile) I'm friends with disabled people, so it keeps spirit, those who are worse than me are many and can survive means I also have to be able to ...

\subsubsection{The ability to analyze the cause of the problem}

When $M$ experienced a slump and tried to commit suicide, $M$ experienced a deadlock to think so he was unable to unravel the problems experienced. M heard a whisper advocating suicide. At this time, M's condition is stable, the whispers that are often heard are still occasionally heard but $\mathrm{M}$ tries to divert his 
attention to other activities such as hoeing the yard, cleaning the house, and chatting with relatives or family. The following is an interview excerpt:

A: How about now, sir, if a problem arises again

M: That problem I said earlier happens to a living person, but yeah I try to find a way out just like that, ... like for example if I hear a whisper as before I will change my mind so I don't think about it anyway yeah what is it in Indonesian ...(laugh) ... I set dangdut, I embraced the field, ironed because I had a laundry or yes I just chatted with neighbors or family ... the most important thing I don't daydream.

\subsubsection{The ability to empathize}

M's ability to empathize is now very good. M shows concern for family and friends with disabilities. The following is an interview excerpt:

M: I am the one who always makes the spirit of a child ... (silence) ... my children are my responsibility, I have to be able to carry out this task well ... I have many disabled friends, and they are sincere so I feel they are my family, and I should help as much as I can..

\subsubsection{The ability to achieve what is intended}

M's enthusiasm for returning to life is well marked by the emergence of desires and aspirations that he now wants to realize. The following is an interview excerpt:

A: Sir, if you know about the goals that you want to achieve in your life, what is it?

M: Hahahahaha ... (laughing) ... lots of sis, I want to make my laundrette business more advanced, I don't want to bother other people, I also want to have a special motorbike for people who only have 1 foot so I feel good if I have to deliver to customers ... of course miss in the future I want to have kind of business that can accommodate workers with disabilities like me ... I'm trying ...

\subsection{Informant 4 (SG)}

SG is the youngest of three siblings who studied in vocational high school, majoring in information technology. After graduating from school, SG had the desire to work in Jakarta, SG applied for jobs to several companies that he wanted, but always failed because there's a problem with his eyes, so he needed glasses for his eyesight. Then SG decided to go home. SG had worked at a paper company in Jogja for a year and then decided to resign because he felt he did not fit his interests. After returning home, SG was unemployed at home for two years. SG feels that it cannot help the family economy because it does not have a steady income. January 21, 2016, SG felt very depressed because he could not work in the place as he wished, so he committed suicide in his room by using the rope in his room. After being assisted by neighbors around, SG was taken to the hospital, then SG realized and felt sorry that he had done so. SG was hospitalized in Grhasia hospital for ten days. Now SG can resume his normal activities, with the help of family, neighbors, and colleagues SG can recover. In 2018 SG got married, and built a new family, so SG felt could be more responsible. SG can share with his wife when experiencing a problem so that SG is no longer like before, who only harbored problems within him. Some factors that support the current condition of SG are:

\subsubsection{Emotional regulation and the ability to control impulses}

SG's current ability to manage emotions has been much better, especially now that SG has become one of the village's apparatuses so that he can provide service for the community and improve his ability to manage his emotions. Here is the interview script:

SG: Well, it used to feel like a bundle of work that suits my expertise how come it's so hard ... But now it's no longer hard. If there are problems, think well, talk to your wife because now there is a wife, so don't bury yourself problems ... that's what makes it look like a dead-end.

SG already has the ability to control oneself when feeling negative emotions that originate from a problem. One of the methods used to regulate his emotions is to tell other people about problems. By telling stories, the pressure experienced by SG was reduced. The following interview excerpts:

B: If you feel deadlocked, how would you manage your emotion? 
SG: Yes, I learned from the experience of yesterday, yes if there is a problem and is considered depressed. Finally later towards that direction (suicide) so if there is a problem, then that's not it ... um ... yes, later there will also be a solution while going on.

SG has begun to be able to control impulses and he felt better. In the past, when experiencing severe problems, SG followed the urge to commit suicide. But, now SG has understood what actions should be taken when the urge to commit suicide arises.

SG: In the past, my mind went everywhere, my rope went up, my rope and then I didn't think of anything.

$B$ : At that time, there was a rope around there, wasn't it planned?

$S G:$ No.

B: Not planned? Spontaneous like that, huh?

SG: yes.

Now:

SG: Yes, learning from the experience of yesterday, yes if there is a problem and is considered depressed. Finally, towards that direction (suicide), so if there is a problem, that's not it ... um ... yes, there will also be a solution while going on.

\subsubsection{Optimism and self-efficacy}

The sense of optimism and acceptance of SG itself has been very good. If in the past, he felt that everything was not as expected, but now he hoped he could realize his aspiration, and it gave a new spirit to SG. The following is an interview excerpt:

A: Is the incident still burdening you?

SG: No, I value life more, and also continue to be excited, because our lives are needed by many people, so we need to be useful.

A: For now, what is your hope?

SG: Right now, it's more towards families because I already have a family, it isn't like before. So yes I can provide family life, especially my parents. SG now has the belief that all problems can be faced, $S G$ believes that every problem has a solution so that $S G$ is more optimistic in facing various difficulties or problems that befall him. The following interview excerpt:

B: So have you still felt deadlocked now?

SG: Yes, I learn from the experience of yesterday, yes if there is a problem and is considered depressed. Finally later towards that direction (suicide) so if there is a problem, then that's not it ... um ... yes later, there will also be a solution while walking.

\subsubsection{The ability to analyze the cause of the problem}

SG's current ability to be able to analyze the root of the problems he faces is very good. Every problem must have a cause and according to SG as long as the problem is not buried by himself he will definitely find a solution. The following is an interview excerpt:

SG: There must be a problem, and there must always be solutions, the problem is now, I have to share it, and the important thing is not to bury the problem by myself...

\subsubsection{The ability to empathize}

SG's empathetic ability is also good, the presence of a wife and children causes empathy for others to develop properly. This is also supported by his work as a village apparatus so that his social life is honed well. The following is an interview excerpt:

SG: ... now that I have a family and children and my wife, I must love and be responsible, I am also the village administrator so I have to serve the community well...

\subsubsection{The ability to achieve what is intended}

SG's current ambitions are quite high, namely achieving success for his family.

A: Is the incident still burdening you?

SG: No, I value life more, and also continue to be excited, because our lives are needed by many people so we need to be useful.

A: For now, what is your hope? 
SG: Right now it's more towards families because I already have a family, it isn't like before. So yes I can provide family life, especially my parents.

Based on interviews with all subjects, it is known that the domains that play a role in the resilience of survivors of suicide attempts in Gunungkidul Regency are; The ability to regulate emotions and the ability to control impulses, optimism and self-efficacy, the ability to analyze the causes of problems, the ability to empathize and the ability to achieve what is desired.

\subsection{The ability to regulate emotion and to control the impulse}

In all four subjects it was found that when a subject wants commits suicide, they cannot control their emotions. Thus, the subject is unable to think clearly and ultimately commit suicide. Now the subject can control his emotions better. This is evident from the subject's ability to stabilize emotions when faced with certain stressors. The subject's way to control his emotions is to tell others, do various other activities so that his mind is distracted, and let go of problems, forgive others who are the source of his stressors and submit everything to God Almighty. When thoughts or suicidal thoughts arise on the subject, a subject claims that he will immediately turn his mind to another thought, or do certain activities so that the thought disappears.

Gross and Thompson [6] define emotional regulation as a series of psychological processes and methods used by individuals to manage perceived emotions in adaptive ways. Emotion regulation is very important to be owned by individuals because when experiencing stress, individuals will be faced with various components of emotions, emotional regulation there acts as a tool that prevents individuals from taking irrational actions [7].

The results of this study are in line with previous studies, including those of Lee, Won, and Jeong [8] who found that the ability to recognize and manage emotions makes individuals have better resilience. Other studies have shown that the ability to refrain from overloading emotions will make individuals more persistent in the face of difficulties and believe in one's own abilities [9]. Besides emotional regulation, another thing that is important for suicide survivors is the ability to control impulses. According to Thistle [9], the ability to control impulses will make individuals more selective in choosing which beliefs will be followed and which will be ignored. Conversely, individuals who display reactive emotions are associated with depressive symptoms and suicidal thoughts [10].

\subsection{Self-efficacy and optimism}

Someone who has low self-efficacy has a pessimistic attitude, a negative mood and considers failure as a heavy burden for his life [11]. According to Bandura [11], self-efficacy determines how people feel, think, behave and motivate themselves. Baron [12] states that self-efficacy refers to speculation and judgment whether a person is able to complete an action, and is associated with the belief that he has the ability to take action expected.

This study is in accordance with research conducted by Florensa [13], who found that high self-efficacy can reduce the risk of depression. These studies show that adolescents who have low self-efficacy have negative perceptions of their ability to cope with stressors so that they are more likely to experience depression than adolescents who have high self-efficacy. Manifestations of depression in adolescents can have various effects such as disruption of social functioning, having difficulty concentrating, experiencing helplessness, and wanting to suicide [13]. Although not all depressed adolescents attempt suicide, depression is said to be the factor most commonly referred to as factors related to suicide [14].

Self-efficacy is inseparable from a sense of optimism about the future. This is because self-efficacy contains a component of self-confidence in dealing with problems in the future. According to Goleman [15], an optimistic attitude can sustain individuals so as not to give up and experience depression when faced with a problem because optimism is a strong hope that everything in life will be overcome properly, despite having many problems and feeling frustrated. Someone who has a high attitude of optimism will be able to reduce depression.

This is consistent with Zafar and Murtaza research [16], which shows that there is a link between optimism and adolescent depression. That is, if adolescents have high optimism, the lower the possibility for depression in adolescents such as suicide. Conversely, the lower the optimism, the higher the depression in adolescents can be. The study of King, Strunk, and Sorter [17] also states that self-efficacy and optimism have a significant contribution in preventing the idea of suicide.

Based on the results of the interviews, all four subjects experienced the worst conditions, so that survivors conducted suicide attempts spontaneously. However, after survivors survived a suicide attempt, survivors can slowly rise from adversity. A sense of optimism and acceptance of the survivor also began to emerge. This is marked by the subject feeling confident that everything that happens to him must be carried out as well as possible. Survivor has also been able to take lessons from the problems and adverse events that they have been experienced. 
Survivor also began to open a new page of his life, this is marked starting a new business for example, that can make money, socializing with neighbors, relatives, and new friends in the disability organization. The subject's family is a reason for the subject to return to life optimism and continue to improve himself.

\subsection{The ability to analyze the cause of the problems}

Based on the results of interviews, it is known that survivors have been able to analyze the problem better. One survivor stated that his attempted suicide was caused by deterioration and stalemate in thinking so that the survivor could not unravel the problem that was being experienced, that's when thoughts of suicide arose. Nowadays, when faced with a problem, survivors are better able to think about it well. The subject seeks to find the cause, analyze, and try to find a solution to the problem. The ability to analyze problems is included in the concept of analytic thinking (analytical thinking). Seligman explained that analytical thinking is a style of thinking that allows individuals to be able to explain something [18]. The ability of analytical thinking is characterized by the ability of individuals to describe problems by understanding their parts, explaining the function of small components for larger components, knowing the reasons why something happened or problem-solving procedures, and being able to evaluate and criticize something [19].

The ability to analyze the cause of a problem will allow individuals to correct mistakes that have been made, and know when the right time to make or avoid a behavior [20]. When someone is faced with a problem and he can analyze it well, the individual will be able to convert the results of his thoughts into behavioural intentions, which will be the actual behavior when facing certain situations [21]. So individuals who have experienced suicide attempts and understand the causes of suicide tend to try to avoid conditions that cause the same stressor. In this research subject, the coping used is different. For example, telling the problem to the family, forgiving other people who are considered to be the source of the problem, to draw closer to God.

\subsection{Empathy}

Based on the results of the interview, it is known that before the incident, the subject lacked concern for others. This is evidenced by the determination of the survivor to carry out a suicide attempt due to experiencing the worst conditions without regard to other family members. Subject's empathy began to emerge after surviving a suicide attempt. This is indicated by the awareness of subjects who have responsibilities for others. One of the causes of empathy for survivors is family. One subject mentioned that he did not want to be a burden on the minds of other family members.

Empathy according to Baron and Byrne [22] is the ability to feel the emotional state of others, feel sympathetic and try to solve problems by taking the perspective of others. Goleman [15] defines empathy as being able to feel what is felt by others, understand the perspectives of others, foster trusting relationships, and align oneself with others. Endah [23] conducted a study showing that empathy affects individual depression and that depression can lead to attempted suicide behavior. Previous research found that empathy is negatively associated with depression in both aspects of empathy, namely the affective and cognitive aspects [24].

\subsection{The ability to achieve what you want}

The ability to achieve what is desired by the survivor makes the survivor feel optimistic and confident to try to achieve other desired expectations. This experience makes the survivor calmer in facing challenges and can estimate how far he is capable of doing something. The hope of the majority of suicide survivors is in career and family aspects. The experience of success is negatively correlated with psychological distress so that individuals can have higher endurance when facing difficulty [25].

\section{CONCLUSION}

In this study, it can be concluded that the factors that support the resilience of suicide survivors are the ability to regulate emotions and the ability to control impulses, self-efficacy and optimism, the ability to analyze the causes of problems, empathy, and the ability to achieve what is desired. Family and community support is also very important so that survivors are able to immediately rise from adversity. He felt needed again, and his existence was cared for as an effort to restore the spirit of life of the survivors. Besides, the opportunity to express aspirations also plays an important role. On average survivors who are rescued feel that they have to convey the problems they face to others in order to be able to unravel the problems that seem to have no way out. 


\section{ACKNOWLEDGEMENTS}

The author would like to thank the Women's Study Center and the Institute of Research and Community Service Ahmad Dahlan University Yogyakarta for providing research funding so that this research can be carried out and completed smoothly.

\section{REFERENCES}

[1] Pelkonen, M., Marttunen, M., "Child and adolescent suicide epidemiology, risk factors, and approaches to prevention," Paediatr Drugs, vol. 5, no. 4, pp. 243-65, 2003. doi:10.2165/00128072-200305040-00004.

[2] Van Orden, K.A., Witte, T.K., Cukrowicz, K.C., Braithwaite, S.R., Selby, E.A., Joiner, T.E. Jr., "The interpersonal theory of suicide," Psychological review, vol. 117, no. 2, pp. 575-600, 2010. doi: https://doi.org/10.1037/a0018697.

[3] Pratiwi, J., Undarwati, A., "Suicide ideation in adolescents in Semarang City (in Indonesian)," Developmental and Clinical Psychology, vol. 3, no. 1, pp. 24-34, 2014.

[4] Nugrawati1, Nursalam, "Hanging yourself as a social deviation against religious norms (in Indonesian)," Equilibrium, vol. 4, no. 1, pp. 11-19, 2016. doi: https://doi.org/10.26618/equilibrium.v6i1.1799.

[5] Sukesi, T., Tentama, F., "Case study of survivors of attempted suicide in Gunungkidul Yogyakarta," Research Report, 2018.

[6] Gross, J.J., Thompson, R.A., "Emotion regulation conceptual: Handbook of emotion regulation," New York: Guilfors Publication, 2009.

[7] Mestre, J.M., Núñez-Lozano, J.M., Gómez-Molinero, R., Zayas, A., Guil, R., "Emotion regulation ability and resilience in a sample of adolescents from a suburban area," Frontiers in psychology, vol. 8, pp. 777-780, 2017. doi: 10.3389/fpsyg.2017.01980.

[8] Lee, S.W., Won, S., Jeong, B., "Moderating effect of emotional awareness on the association between maltreatment experiences and resilience," Personality and Individual Differences, vol. 148, pp. 38-44, 2019. https://doi.org/10.1016/j.paid.2019.05.037.

[9] Widuri, E.L., "Emotional regulation and resilience in first year students (in Indonesian)," Humanitas, vol. 9, no. 2, pp. 147-156, 2012. doi: http://dx.doi.org/10.26555/humanitas.v9i2.341.

[10] Shapero, B.G., Farabaugh, A., Terechina, O., DeCross, S., Cheung, J.C., Fava, M., Holt, D.J., "Understanding the effects of emotional reactivity on depression and suicidal thoughts and behaviors: Moderating effects of childhood adversity and resilience," Journal of Affective Disorders, vol. 245, pp. 419-427, 2019. doi:10.1016/j.jad.2018.11.033.

[11] Bandura, A., "Self-efficacy and the construction of an optimistic self," Reaching Today's Youth, vol. 4, no. 4, pp. 1822. 2000.

[12] Baron, K.G., Berg, C.A., Czajkowski, L.A., Smith, T.W., Gunn, H.E., Jones, C.R., "Self-efficacy contributes to individual differences in subjective improvements using CPAP," Sleep and Breathing, vol. 15, no. 3, pp. 599-606, 2011. doi: 10.1007/s11325-010-0409-5.

[13] Florensa, K.B.A., Wardani, I.Y., "Improved self-efficacy and decrease of depression in teenagers with cognitive behavior therapy," Nursing Journal of Indonesia, vol. 19, no. 3, pp. 169-175, 2016. doi: 10.7454/jki.v19i3.474.

[14] Hawton, K., Casañas I Comabella, C., Haw, C., Saunders, K., "Risk factors for suicide in individuals with depression: A systematic review," Journal of affective disorders, vol. 147, no. 1-3, pp. 17-28, 2013. doi: https://doi.org/10.1016/j.jad.2013.01.004.

[15] Goleman, "Emotional Intelligence: Why it can matter more than IQ," New York: Bantam Dell, 2006.

[16] Zafar, A., Murtaza, H., "Optimism and Depression among Students of University of Gujrat," International Journal of Applied Psychology, vol. 8, no. 3, pp. 41-46. doi:10.5923/j.jjap.20180803.01.

[17] King, K.A., Strunk, C.M., Sorter, M.T., "Preliminary effectiveness of surviving the teens suicide prevention and depression awareness program on adolescents' suicidality and self-efficacy in performing help-seeking behaviors," Journal of School Health, vol. 81, no. 9, pp. 581-590, 2011. doi: 10.1111/j.1746-1561.2011.00630.x.

[18] Reivich, Shatte, "The Resiliency Factor," New York: Three Rivers Press, 2015.

[19] Kao, C.Y., "Exploring the relationships between analogical, analytical, and creative thinking," Thinking Skills and Creativity,' vol. 13, pp. 80-88, 2014. doi:https://doi.org/10.1016/j.tsc.2014.03.006.

[20] Broomhall, A.G., Phillips, W.J., Hine, D.W., Loi, N.M.,, "Upward counterfactual thinking and depression: A metaanalysis," Clinical Psychology Review, vol. 55, pp. 56-73, 2017. doi: https://doi.org/10.1016/j.cpr.2017.04.010.

[21] Epstude, K., Jonas, K.J., "Regret and counterfactual thinking in the face of inevitability: The case of HIV-positive men," Social Psychological and Personality Science, vol. 6, no. 2, pp. 157-163, 2015. https://doi.org/10.1177/1948550614546048.

[22] Baron, R.A., Byrne, D., "Social Psychology," Boston: Allyn and Bacon, 1997.

[23] Endah, M., Ratih, A., "The Influence of Resilience and Empathy toward Depression of Adolescents," Jurnal Psikologi, vol. 14, no. 1, pp. 60-75, 2018.

[24] Cusi, A.M., MacQueen, G.M., Spreng, R.N., McKinnon, M.C., "Altered empathic responding in major depressive disorder: Relation to symptom severity, illness burden, and psychosocial outcome," Psychiatry research, vol. 188, no. 2, pp. 231-236, 2011. doi: 10.1016/j.psychres.2011.04.013.

[25] Hosseini, S.A., Besharat, M.A., "Relation of resilience whit sport achievement and mental health in a sample of athletes," Procedia-Social and Behavioral Sciences, vol. 5, pp. 633-638, 2010. doi:10.1016/j.sbspro.2010.07.156. 